Check for updates

Cite this: RSC Adv., 2017, 7, 52729

\title{
PES magnetic microspheres: preparation and performance for the removal of endocrine disruptor-BPA
}

\author{
Ting Yu, (iD a Minle Peng, (D) a Jiacao Yang, (D) ${ }^{a}$ Xiang Huang, (D) ${ }^{a}$ Shengru Long, (D) ${ }^{b}$ \\ Gang Zhang, (D) ${ }^{\mathrm{b}}$ Xiaojun Wang (D) ${ }^{* \mathrm{bc}}$ and Jie Yang (D) *bd
}

In this paper, polyethersulfone (PES) magnetic microspheres were prepared via an in situ reaction method. Firstly, the PES microspheres were produced by an electrospray method and then the magnetic properties were delivered to the microspheres through in situ reaction. Scanning electron microscopy (SEM) coupled with image analysis software, transmission electron microscopy (TEM), and X-ray diffraction (XRD) were employed to investigate the structure and morphology of the magnetic microspheres. The results indicate that the majority of the magnetic nanoparticles are dispersed uniformly and embedded into the surface of the PES electrosprayed microspheres. A vibrating sample magnetometer was used to evaluate the magnetic properties of the PES magnetic microspheres and the saturation magnetization values were found to be up to $23.96 \mathrm{emu}^{-1}$. A separation test showed that the prepared magnetic microspheres can realize fast separation under an external magnetic field. Additionally, compared with the original microsphere counterparts, PES magnetic microspheres exhibited better adsorption capacity and reuse performance in adsorption tests. These results indicate that the PES in situ magnetic microspheres have the potential to be used in water treatment and environmental depuration.

Received 2nd September 2017 Accepted 8th November 2017

DOI: 10.1039/c7ra09761a

rsc.li/rsc-advances structure and large specific surface area. ${ }^{12-15}$ Our previous research shows that PES electrosprayed microspheres have a good performance in adsorption of BPA. ${ }^{16,17}$

However, for the practical application in adsorption, the ability of directional separation is also an import factor besides the adsorption capacity. Otherwise, it will cause secondary pollution of water environment. Controlling the movement of the microspheres is difficult due to their micro-scale size. It is of great important to find a convenient and efficient method to separate the microspheres from water environment. It is a promising method to prepare the magnetic microspheres to solve this issue. ${ }^{18}$

Magnetic polymer microspheres possess great magnetic properties so that they can move directionally in the external magnetic field. In this way they can be separated directly from the environment. Magnetic microspheres have attracted much attention in recent years and will be potentially used in many fields, such as wastewater treatment, ${ }^{19,20}$ enzyme immobilization, ${ }^{21}$ magnetic resonance imaging (MRI) ${ }^{22}$ and cell separation, ${ }^{23}$ etc. Conventionally, the preparation methods include monomer polymerization ${ }^{24,25}$ and embedding method, ${ }^{26,27}$ both involving the synthesis of magnetic particles as well as the microspheres and the following binding of particles and microspheres. However, the magnetic microspheres prepared in these ways have some drawbacks including low magnetic particles content and uneven distribution of particles on microspheres. For these shortcomings, in situ reaction is 
a promising solution. In this way, magnetic particles are generated in situ on synthesized microspheres. The prepared microspheres are soaked in the solution of ferric ion first so that the ferric ions are adsorbed onto the microspheres and then the adsorbed ions are turned into magnetic particles in situ through adjusting the $\mathrm{pH}$ and temperature. ${ }^{28-31}$ With this method, the magnetic microspheres are obtained.

Literatures concerning the in situ reaction are not much, and most of them are limited to several kinds of polymer, such as chitosan $^{28-30}$ or cellulose. ${ }^{31}$ The conventional preparation methods include sol-gel transition and microemulsion approaches. Magnetic microspheres prepared via these ways are hindered by the following shortcomings such as long preparation cycles, application of surfactants and co-surfactants which do harm to the environment to assist the fabrication of microspheres and uneven microspheres diameters. Considering the advantages mentioned above, in this paper, magnetic microspheres based on PES, a special engineering polymer with good heat and chemical resistance and sprayability, were prepared by in situ reaction combined with the electrospraying, a novel route for the preparation of magnetic microspheres. The PES magnetic microspheres were found to have excellent magnetic and adsorption properties, having potential applications in water treatment and environment depuration especially for the adsorption of endocrine disruptor-BPA.

\section{Experimental}

\subsection{Materials}

PES (Ultrason E 6020P) with an intrinsic viscosity of $0.34 \mathrm{dL} \mathrm{g}^{-1}$ in dimethyl sulfoxide (DMSO) at $303.2 \mathrm{~K}$ was purchased from BASF Chemical Co. (Germany) and the molecular weight of PES is about $50000 \mathrm{~g} \mathrm{~mol}^{-1}$. Bisphenol A (BPA) was purchased from Changlian Chemical Co. (China). Solvent used in this study, such as $N, N$-dimethylformamide (DMF), $\mathrm{NaOH}, \mathrm{H}_{2} \mathrm{O}_{2}(30 \%)$ and $\mathrm{FeCl}_{2} \cdot 4 \mathrm{H}_{2} \mathrm{O}$ were purchased from Kelong Chemical Co. (China). All the chemicals are of analytical grade and were used without further purification unless described. Deionized water used throughout the study was lab homemade.

\subsection{Preparation of in situ magnetic microspheres}

PES was dissolved in DMF at $60{ }^{\circ} \mathrm{C}$ for $4 \mathrm{~h}$ until the solution became homogeneous, and its concentration is $0.10 \mathrm{~g} \mathrm{~mL}^{-1}$. For preparing microspheres, the solution was placed in a $50 \mathrm{~mL}$ syringe, to which a capillary tip of $0.5 \mathrm{~mm}$ inner diameter was attached. A direct current high-voltage generator (BGG, Beijing Electro-mechanical Research Institute Supervoltage Technique Company) was used to provide a voltage of $10 \mathrm{kV}$. The positive electrode of high-voltage power supply was connected to the capillary tip. The grounded electrode was connected to a metallic collector immersed in a water bath. The distance between the tip and the collector was maintained at $6 \mathrm{~cm}$ (ref. 17) and the flow rate was fixed at $1 \mathrm{~mL} \mathrm{~h}^{-1}$. The spraying stream is broken up after moving a certain distance, and then electrosprayed microspheres were collected in the water bath. Then PES electrosprayed microspheres were immersed in deionized water and washed for $48 \mathrm{~h}$ at $80{ }^{\circ} \mathrm{C}$ to remove the solvent, and then they were filtered and dried.

$0.01 \mathrm{~g}$ PES electrosprayed microspheres (PEM) and different contents of $0.5,1.0,1.5,2.0 \mathrm{~g} \mathrm{FeCl}_{2} \cdot 4 \mathrm{H}_{2} \mathrm{O}$ (named as M5, M10, M15, M20) were put into each of four tubes, and $20 \mathrm{~mL}$ deionized water was added under nitrogen atmosphere. Afterward, the tubes were dispersed in ultrasonic instrument (KQ-500, Kun Shan Ultrasonic Instruments Co., Ltd) at $40{ }^{\circ} \mathrm{C}$ for $48 \mathrm{~h}$ to make the microspheres achieve the goal of $\mathrm{Fe}^{2+}$ adsorption equilibrium. Subsequently, the materials were centrifuged at $5000 \mathrm{rpm}$ for $10 \mathrm{~min}$, and the supernatant liquid was poured out. And then, $20 \mathrm{~mL} \mathrm{NaOH}$ aqueous solution $\left(0.02 \mathrm{~mol} \mathrm{~L}^{-1}\right)$ was added into the tubes which were put into a water bath $\left(60{ }^{\circ} \mathrm{C}\right.$ for $\left.4 \mathrm{~h}\right)$. After that, $10 \mathrm{~mL} \mathrm{H}_{2} \mathrm{O}_{2}(1 \mathrm{wt} \%)$ was added, and then put the tubes into a $30{ }^{\circ} \mathrm{C}$ water bath for $4 \mathrm{~h}$. Finally, the microspheres were isolated, and dried at $100{ }^{\circ} \mathrm{C}$ for $24 \mathrm{~h}$. According to the above steps, PES in situ magnetic microspheres (PMM) were obtained. The certain experimental parameters are shown in Table 1, and the preparation procedure is illustrated in Scheme 1.

\subsection{Microscopy and structure of the microspheres}

The morphology of PEM and PMM was observed by scanning electron microscopy (SEM Inspector F, FEI Company, all operation at an accelerating voltage of $20 \mathrm{kV}$ ). The samples were coated by an E-1045 ion sputter coater with $\mathrm{Au} / \mathrm{Pd}$ to reduce charging. The diameters of PEM were measured by an image analysis software of Image $\mathrm{J}$ based on the SEM results. The diameters of more than 200 PEM were randomly measured for statistic significance. Besides, the size and morphology of magnetic nanoparticles were observed by a transmission electron microscopy (TEM) instrument (Hitachi, JEM-2100F), using an accelerating voltage of $200 \mathrm{kV}$.

The ferrite content of dried PMM was measured on a thermo gravimetric analysis (TGA) instrument (TA Instruments, Q500) and heated from room temperature to $700{ }^{\circ} \mathrm{C}$ at a heating rate of $20{ }^{\circ} \mathrm{C} \min ^{-1}$ under nitrogen atmosphere (flow rate $\left.20 \mathrm{~mL} \mathrm{~min}^{-1}\right)$.

The crystal structure of PMM was measured on a wide-angle X-ray diffraction (XRD) diffractometer (X'Pert pro-MPD, Philips). The XRD patterns with $\mathrm{Cu} \mathrm{K} \alpha$ radiation at $40 \mathrm{kV}$ and $35 \mathrm{~mA}$ were recorded in the region of $2 \theta$ from 10 to $70^{\circ}$.

\subsection{Magnetic characterization and separation experiment}

The magnetic properties of the PMM were measured with a vibrating sample magnetometer (VSM) at $300 \mathrm{~K}$ and within the magnetic intensity range from -15000 Oe to +15000 Oe.

Table 1 The preparation parameters of the PMM

\begin{tabular}{llllll}
\hline Sample & PEM $(\mathrm{g})$ & $\begin{array}{l}\mathrm{FeCl}_{2} \cdot 4 \mathrm{H}_{2} \mathrm{O} \\
(\mathrm{g})\end{array}$ & $\begin{array}{l}\mathrm{H}_{2} \mathrm{O} \\
(\mathrm{mL})\end{array}$ & $\mathrm{NaOH}(\mathrm{mL})$ & $\mathrm{H}_{2} \mathrm{O}_{2}(\mathrm{~mL})$ \\
\hline M5 & 0.01 & 0.5 & 20 & 20 & 10 \\
M10 & 0.01 & 1.0 & 20 & 20 & 10 \\
M15 & 0.01 & 1.5 & 20 & 20 & 10 \\
M20 & 0.01 & 2.0 & 20 & 20 & 10
\end{tabular}



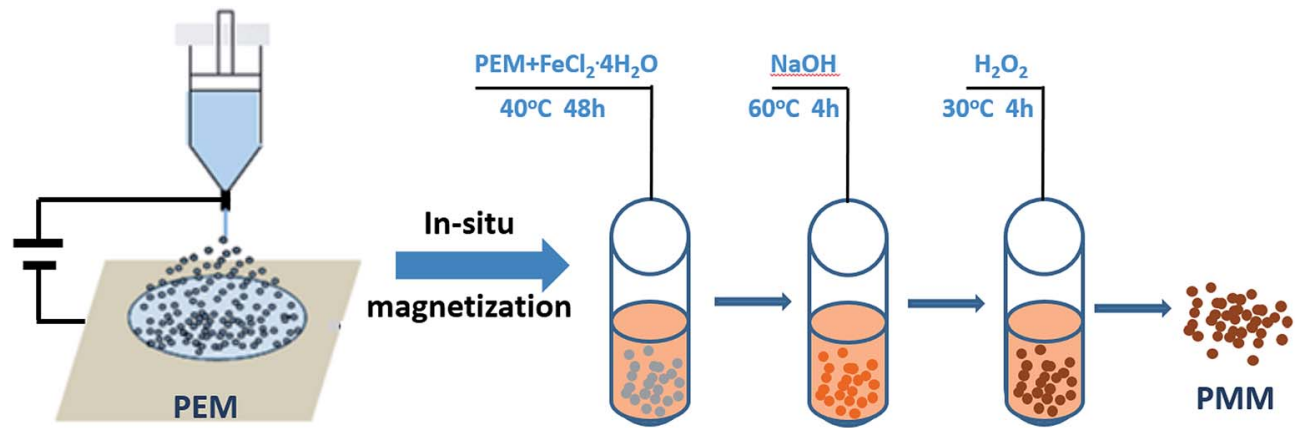

Scheme 1 The preparation procedure of PMM.

Moreover, $4 \mathrm{mg}$ PMM were put into a sample bottle, and $10 \mathrm{~mL}$ deionized water was also added. After stirring for $10 \mathrm{~min}$, microspheres were evenly dispersed. Then permanent magnet was placed in one side of the bottle, and movement of magnetic microspheres was recorded in a certain period of time. The microspheres were separated from the liquid phase by the permanent magnet as they have almost reached the wall of the bottle. Then the liquid phase was poured, and PMM were dried.

\subsection{Adsorption experiments}

$3 \mathrm{mg}$ PEM and M10 microspheres were dispersed in $10 \mathrm{~mL}$ BPA solution (BPA was dissolved in ethanol and then diluted with deionized water.) with initial concentration of $100 \mu \mathrm{mol} \mathrm{L}{ }^{-1}$, $200 \mu \mathrm{mol} \mathrm{L}^{-1}$ and $300 \mu \mathrm{mol} \mathrm{L}{ }^{-1}$, respectively. And the mixtures were shaken at $20{ }^{\circ} \mathrm{C}$. After adsorption, a permanent magnet was used to separate the adsorbent and the supernatants were collected. The BPA concentrations in the supernatant were detected by a UV-vis spectrophotometer (UV-2310II, Shanghai TECHCOMP, Shanghai, China) at the wavelength of $276 \mathrm{~nm}$. The adsorbed capacity of microspheres was calculated as following:

$$
q_{t}=\frac{\left(C_{0}-C_{t}\right) \times V}{M}
$$

where $q_{t}$ is the adsorbed BPA amount per gram of microspheres at time $t\left(\mu \mathrm{mol} \mathrm{g}{ }^{-1}\right) ; C_{0}$ is the initial concentration of BPA solutions $\left(\mu \mathrm{mol} \mathrm{L}{ }^{-1}\right) ; C_{t}$ is the concentration at time $t\left(\mu \mathrm{mol} \mathrm{L}^{-1}\right) ; V$ is the volume of BPA solution used in the experiment (L); and $M$ is the weight of microspheres $(\mathrm{g})$.

The adsorption kinetic behaviors of M10 microspheres can be expressed by the pseudo-first-order adsorption model ${ }^{32}$

$$
\ln \left(q_{\mathrm{e}}-q_{t}\right)=\ln q_{\mathrm{e}}-\frac{K_{1}}{2.303} t
$$

or the pseudo-second-order adsorption model ${ }^{33}$

$$
\frac{t}{q_{t}}=\frac{1}{K_{2} q_{\mathrm{e}}^{2}}+\frac{1}{q_{\mathrm{e}}} t
$$

where $q_{t}$ is the adsorbed BPA amount per gram of microspheres at time $t\left(\mu \mathrm{mol} \mathrm{g}{ }^{-1}\right), q_{\mathrm{e}}$ is the theoretical adsorption equilibrium amount $\left(\mu \mathrm{mol} \mathrm{g}{ }^{-1}\right), K_{1}$ is the rate constant of pseudo-first-order kinetics equation $\left(\mathrm{min}^{-1}\right)$, and $K_{2}$ is the rate constant of pseudosecond-order kinetics equation $\left(\mathrm{g} \mu \mathrm{mol}^{-1} \mathrm{~min}^{-1}\right)$.
The reuse performance of the M10 microspheres was also tested. $3 \mathrm{mg}$ M10 was added to a BPA aqueous solution $(10 \mathrm{~mL}$, $300 \mu \mathrm{mol} \mathrm{L}{ }^{-1}$ ) and shaken for $24 \mathrm{~h}$ (to ensure that equilibrium adsorption reached totally) at $20{ }^{\circ} \mathrm{C}$. The mixture was then separated with a permanent magnet and the concentration of BPA in aqueous solution was determined by a UV-vis spectrophotometer. While the desorption process was conducted in $10 \mathrm{~mL}$ ethanol with shaking at $20^{\circ} \mathrm{C}$ for $24 \mathrm{~h}$ to ensure complete removal of the residual BPA in M10. After desorption, separation of the adsorbent and the aqueous phase was achieved with the help of the same permanent magnet. The separated M10 was washed with deionized water three times, and they were not dried after separated from deionized water, because the dried microspheres dispersed poorly in BPA aqueous solution, which would affect the adsorption performance of M10. Consequently, the regenerated M10 was added into a new BPA aqueous solution $\left(10 \mathrm{~mL}, 300 \mu \mathrm{mol} \mathrm{L}{ }^{-1}\right)$ to start the next cycle of adsorption. Adsorption and desorption were repeated for five times by using the same M10 magnetic microspheres.

All experiments were performed in triplicate.

\section{Results and discussion}

\subsection{The structure of microspheres}

In order to study the surface morphology of the microspheres, the scanning electronic microscopy was conducted, and the images are shown in Fig. 1a. It is clearly visible that these microspheres exhibit spherical shape with porous structure
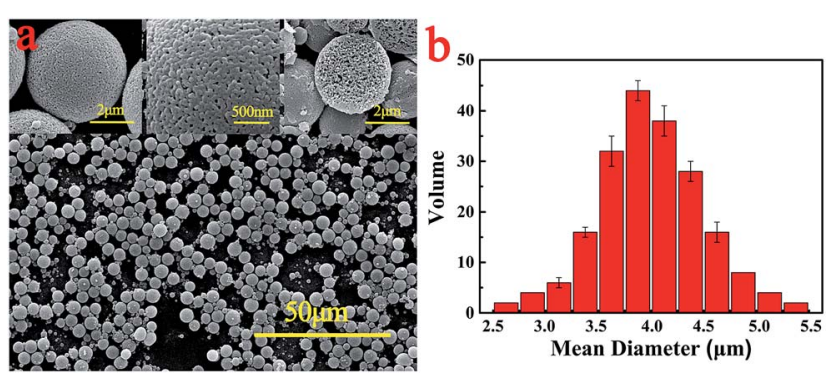

Fig. 1 (a) Low and high-magnification SEM images of PEM with the cross-section images on the right top. (b) The diameter distribution of PEM. 

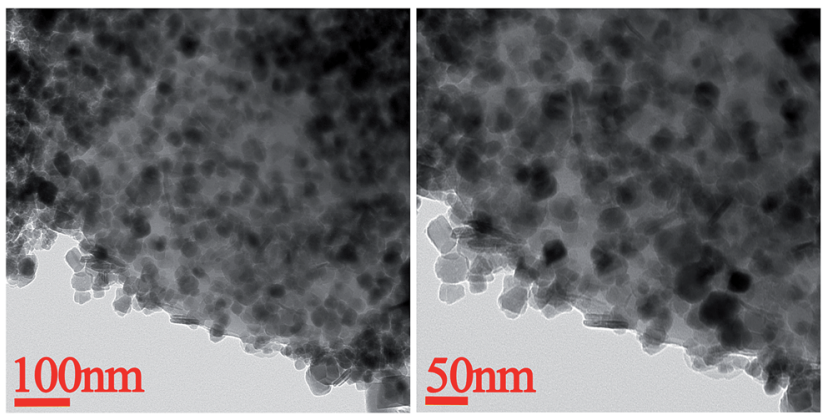

Fig. 2 TEM images of the PMM.

(mean diameter about $32 \mathrm{~nm}$ ). The formation process of porous PEM can be divided into two steps. The first step is electrospraying which was accompanied with rapid evaporation of solvent DMF while the second step is the figuration of microspheres in coagulation bath with the liquid-liquid phase separation which occurred by rapid exchange of the solvent DMF and no-solvent water. ${ }^{34}$ According to the forming mechanism of microspheres, the microspheres interior should be porous structure. In order to observe the internal structure of PEM, a facile method ${ }^{35}$ reported earlier by our group was adapted. The insert in the right top corner of Fig. 1a shows the image of the cross section of PEM, and a uniform cellular structure can be seen.

Meanwhile, the size distribution of microspheres is counted with Image J, and the result is shown in Fig. 1b. Their diameters ranged from $2.5 \mu \mathrm{m}$ to $5.5 \mu \mathrm{m}$, presenting an average diameter of about $3.6 \mu \mathrm{m}$, and the size distribution fitted the Gaussian distribution on the whole.

The porous PES electrosprayed microspheres were used as the solid template microreactor for co-precipitation reaction. This could be explained by the fact that $\mathrm{Fe}^{2+}$ could be readily embedded into the PEM matrix, and were bound to the PEM via physical adhesion, firstly. Then with the increase of $\mathrm{pH}, \mathrm{Fe}(\mathrm{OH})_{2}$ were precipitated on the surface of PEM. $\mathrm{Fe}(\mathrm{OH})_{2}$ were oxidized to ferrite by $\mathrm{H}_{2} \mathrm{O}_{2}$ and the reaction systems were kept for a long time, which make ferrite obtain better magnetic properties. Thus the ferrite nanoparticles were synthesized in situ on PEM to form nanocomposite. The corresponding chemical reactions are shown in following equations.

$$
\begin{gathered}
\mathrm{Fe}^{2+}+2 \mathrm{OH}^{-} \rightarrow \mathrm{Fe}(\mathrm{OH})_{2} \\
3 \mathrm{Fe}(\mathrm{OH})_{2}+\mathrm{H}_{2} \mathrm{O}_{2} \rightarrow \mathrm{Fe}_{3} \mathrm{O}_{4}+4 \mathrm{H}_{2} \mathrm{O} \\
2 \mathrm{Fe}(\mathrm{OH})_{2}+\mathrm{H}_{2} \mathrm{O}_{2} \rightarrow \mathrm{Fe}_{2} \mathrm{O}_{3}+3 \mathrm{H}_{2} \mathrm{O}
\end{gathered}
$$

TEM images of PMM are shown in Fig. 2. The results revealed that the ferrite nanoparticles which are proved by the following XRD results, were approximately spherical with diameter about $30 \mathrm{~nm}$ which is in good agreement with the value of the pore diameter obtained from Fig. 1a, and they dispersed uniformly in the PEM matrix. The size of the ferrite particles hardly changed, which indicates that the pores on the surface of the PEM acted as microreactors to limit the growth of
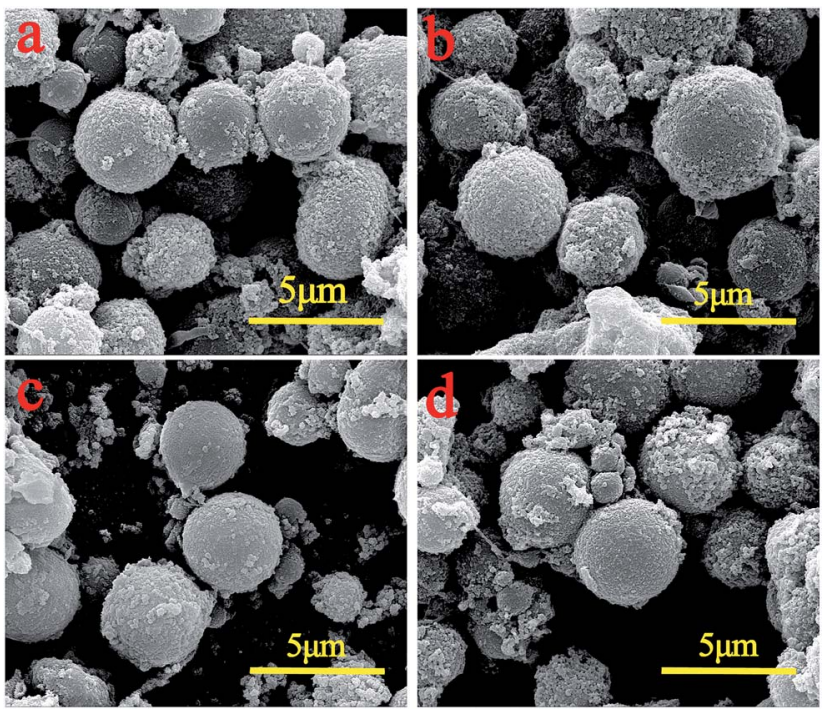

Fig. 3 SEM images of the PMM prepared with different parameters. (a) M5; (b) M10; (c) M15; (d) M20.

the ferrite. And the homogenous distribution demonstrates that the ferrite nanoparticles were fabricated successfully by in situ reaction on PEM pores which were used as the microreactors to form ferrite nanoparticles.

Fig. 3 shows the SEM images of four kinds of PMM. The images display the morphology of PMM, indicating their spherical shape. The rough surface of PMM is significantly different from that of the raw PEM. This indicates that a large amount of in situ generated ferrite nanoparticles had accumulated on the surface of the PEM. And the pore volume of PMM was much smaller than that of PEM. This indicates that the ferrite nanoparticles have occupied of the pore space of the PEM. From the SEM images of M15 and M20, it can be found that some ferrite particles dispersed between the polymeric microspheres. It means that due to the increasing concentration of $\mathrm{FeCl}_{2} \cdot 4 \mathrm{H}_{2} \mathrm{O}$ in solution, M15 and M20 microspheres may adsorb more $\mathrm{Fe}^{2+}$. But the attachment sites on the surface of each microsphere are limited, and part of ferrite nanoparticles in M15 or M20 cannot attach to the microspheres, and became freestanding instead. And the free ferrite nanoparticles tend to agglomerate as shown in Fig. $3 \mathrm{c}$ and d. So the ferrite contents (as shown in Table 2) of M10, M15 and M20 didn't change obviously with the increase of $\mathrm{Fe}^{2+}$ content. This further indicates that the pores of the PEM act as micro-chambers to control the embedment of ferrite nanoparticles. Besides, according to Table 2, it could not be found appreciable change

Table 2 The mean diameters and ferrite content of PMM

\begin{tabular}{lll}
\hline Sample & Mean diameter $(\mu \mathrm{m})$ & Ferrite content $(\%)$ \\
\hline M5 & $3.7 \pm 0.594$ & 22.37 \\
M10 & $3.9 \pm 0.603$ & 35.99 \\
M15 & $3.8 \pm 0.587$ & 38.20 \\
M20 & $3.9 \pm 0.579$ & 38.53
\end{tabular}




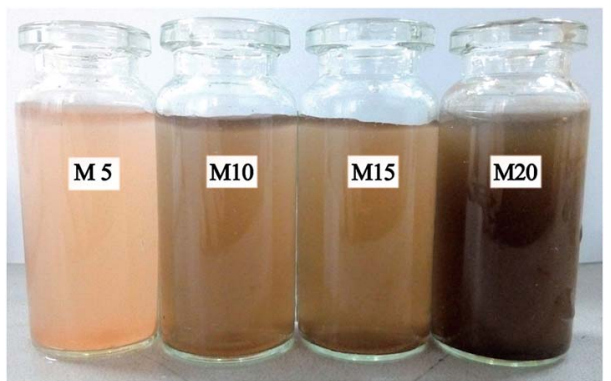

Fig. 4 The photograph of PMM dispersed in water.

in the average diameter of the raw PEM and PMM. This could be explained that the generation of the ferrite nanoparticles occurred in the pores of the PEM, and the ferrite nanoparticles occupied only the surface of PEM, keeping the shape and size of original microspheres, which also revealed that the pores on the surface of PEM were used successfully as reaction chambers.

In addition, $4 \mathrm{mg}$ of each kind of PMM were dispersed in $10 \mathrm{~mL}$ deionized water by ultrasonic as shown in Fig. 4. Clearly, the color of each suspension liquid changed from light orange to light brown and then to dark brown with increasing the concentration of $\mathrm{FeCl}_{2} \cdot 4 \mathrm{H}_{2} \mathrm{O}$.

Therefore, XRD was employed to study the actual reason for why the color altered among the samples. Fig. 5 shows the XRD patterns of these four kinds of PMM and the original PEM. Since PES resin is a kind of amorphous polymers, there is no crystal structure can be detected in the original PEM. Conversely, all the magnetic microspheres exhibit crystallization peaks, which confirm the presence of the ferrite nanoparticles and imply the success of the in situ reaction. By comparing with the peaks, M5 display some distinct crystallization peaks which are quite different from those of M10, M15 and M20. M5 profiles exhibit three groups of peaks at $2 \theta=$ $33.15,35.61,49.48$ and $54.09^{\circ}$, which can be assigned to the (104), (110), (024) and (116) planes of $\mathrm{Fe}_{2} \mathrm{O}_{3}$ (JCPDS card no. 898104), respectively. However, M10, M15 and M20 displayed some distinct peaks at $2 \theta$ values of $30.24,35.60,43.24,53.70$, 57.16 and $62.57^{\circ}$, assigned to the (220), (311), (400), (422), (511) and (440) planes of $\mathrm{Fe}_{3} \mathrm{O}_{4}$ (JCPDS card no. 65-3107). These

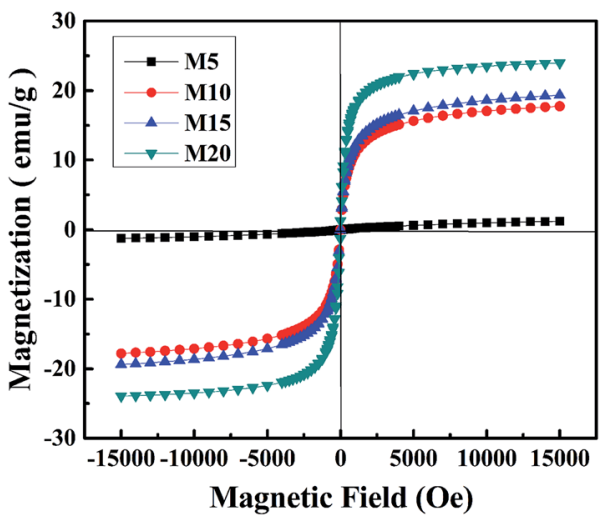

Fig. 6 The magnetic hysteresis curves of PMM.

results indicate that $\mathrm{Fe}_{2} \mathrm{O}_{3}$ nanoparticles were generated on the surface of $\mathrm{M} 5$, nevertheless, $\mathrm{Fe}_{3} \mathrm{O}_{4}$ nanoparticles were formed during the in situ reaction in M10, M15 and M20 samples. The reason for the color alternation may be attributed to the same amount of $\mathrm{NaOH}$ and $\mathrm{H}_{2} \mathrm{O}_{2}$ but different $\mathrm{Fe}^{2+}$ concentration. The concentration of $\mathrm{Fe}^{2+}$ in $\mathrm{M} 5$ is the lowest one, so the $\mathrm{Fe}^{2+}$ in the pores on the surface of microspheres was totally oxidized into $\mathrm{Fe}^{3+}$ which exhibited as $\mathrm{Fe}_{2} \mathrm{O}_{3}$ in XRD profiles, while the $\mathrm{Fe}^{2+}$ on the surface of M10, M15 and M20 microspheres were oxidized partially into $\mathrm{Fe}_{3} \mathrm{O}_{4}$.

In a word, in situ generated ferrite nanoparticles have been successfully accumulated in the pores on the surface of PEM, which obviously changes the properties of microspheres such as the following magnetic properties.

\subsection{Magnetic properties}

To investigate the magnetic property of the PMM, VSM test was carried out and the results are shown in Fig. 6. The magnetization of PMM increased with enhancing the intensity of magnetic field. The magnetization of M5 is weak and shows a lack of saturation, while the others exhibit an extremely small hysteresis loop and low coercivity, which is a typically characteristic of superparamagnetic materials. And the saturation magnetization of M10, M15 and M20 obtained from the
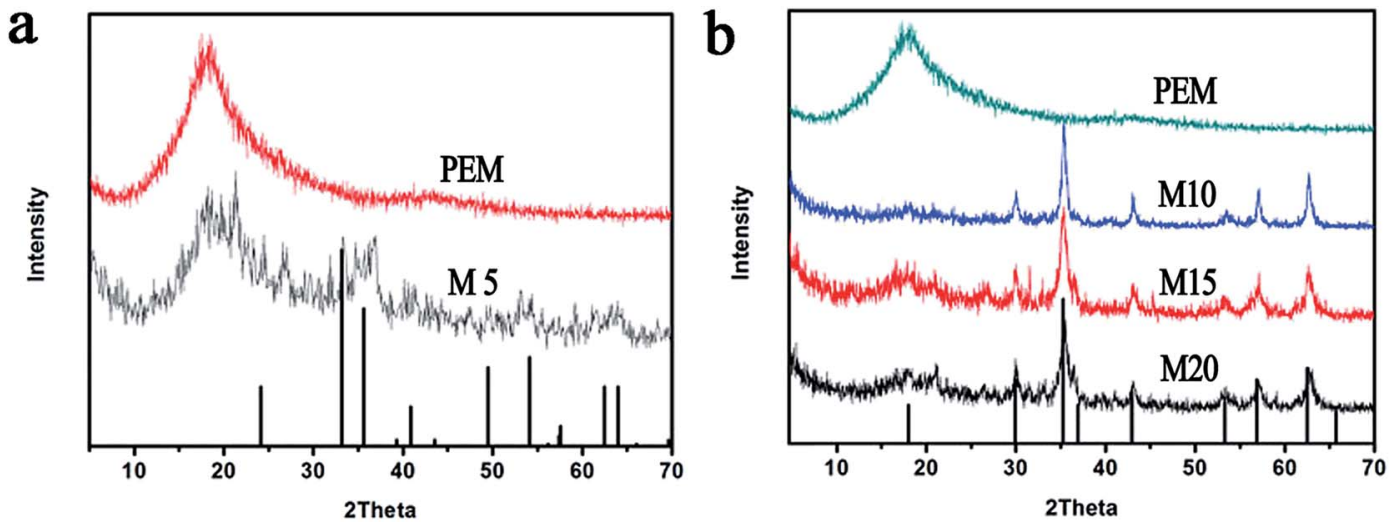

Fig. 5 XRD profiles of PEM and PMM (the black lines are standard crystallization peaks for (a) $\mathrm{Fe}_{2} \mathrm{O}_{3}$ and $\left.(\mathrm{b}) \mathrm{Fe}_{3} \mathrm{O}_{4}\right)$. 
hysteresis loop is $17.78,19.38$ and 23.96 emu $^{-1}$, respectively. Compared with M5 whose maximum magnetization is about

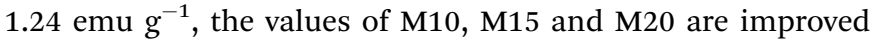
more than 10 times. The results reveal that the microspheres with $\mathrm{Fe}_{3} \mathrm{O}_{4}$ nanoparticles possess better magnetic properties than those with $\mathrm{Fe}_{2} \mathrm{O}_{3}$. Furthermore, the saturation magnetization increased slightly with the increasing of $\mathrm{Fe}_{3} \mathrm{O}_{4}$ content.

It is obvious that the more $\mathrm{Fe}^{2+}$ in the solution, the higher saturated magnetization of microspheres in magnetic hysteresis loop. To study the relationship between the concentration of $\mathrm{Fe}^{2+}$ and the separating performance of the microspheres, the separation experiment was conducted and the results are shown in Fig. 7. Actually, separation performance does not present the same trend as the saturated magnetization results.

From Fig. 7, it can be observed that the PMM possessed a sensitive magnetic response so they could move directionally and align quickly by applying an external magnetic field. It can also be observed that supernatant fluid of M5 is still turbid after 40 minutes, but for M10 microspheres, the supernatant fluid became transparent and the absorbance detected by UV-vis spectrophotometer was 0.484 after $5 \mathrm{~min}$, indicating that M10 microspheres had been separated completely from the water environment. And M15 and M20 required more time to achieve the similar result in order. Besides, on account of the gradual increase of free $\mathrm{Fe}_{3} \mathrm{O}_{4}$ nanoparticles in M10, M15 and M20, the Brownian motion of the particles was more fierce than the motion alongside the magnetic field, so the worst separation performance occurred in M20 whose saturated magnetization was highest. Furthermore, to research the mechanism, supernatant fluid of M20 was extracted after directional separation that lasted for $20 \mathrm{~min}$ in deionized water, dried and tested via SEM as shown in Fig. 8, which further confirmed the existence of unbounded nanoparticles having spherical shape and the

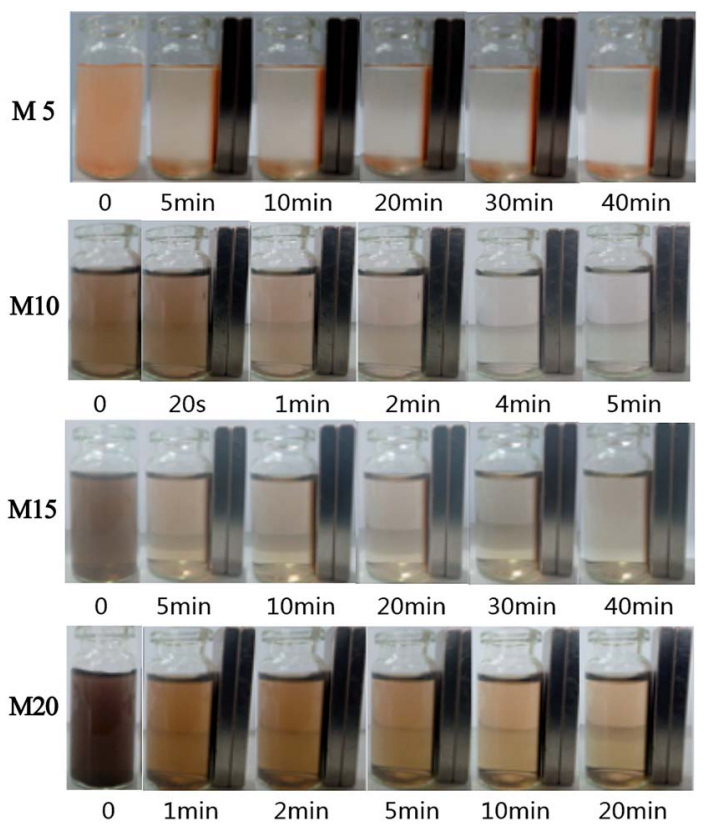

Fig. 7 The photographs of the magnetic separation of the PMM prepared with different $\mathrm{Fe}^{2+}$ concentration.

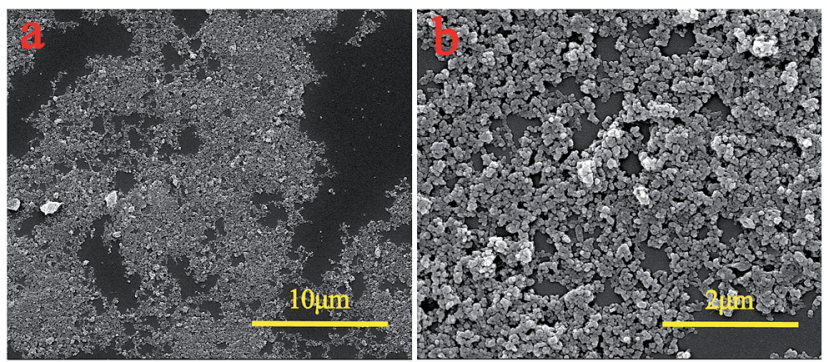

Fig. 8 The Low (a)-and high (b)-magnification SEM images of the M20 supernatant after the magnetical separation.

diameter of 26-35 $\mathrm{nm}$ and the result is in good agreement with the values obtained from Fig. 2. It suggests that there are lots of free ferrite nanoparticles in M20 suspensoid which may offer no contribution to the separation performance of the microspheres.

In view of the above results, the M10 in situ magnetic microspheres show the best directional separation performance. So the M10 in situ magnetic microspheres will be mainly used for adsorption of BPA.

\subsection{Adsorption properties}

The dynamic adsorption curves of the M10 sample for BPA in its aqueous solution are shown in Fig. 9. It indicates that the M10 microspheres present a high rate of adsorption in the beginning 60 min when BPA entered some easy accessible surface pore sites and binding with the microspheres, and then the adsorption rate slowed down might be due to the BPA molecular diffusing into some deeper pores. ${ }^{14}$ Finally, the adsorption equilibrium reached and the equilibrium adsorption amounts were $115,165,273 \mu \mathrm{mol} \mathrm{g}{ }^{-1}$, respectively, when the concentration of BPA aqueous solution was 100, 200 and $300 \mu \mathrm{mol} \mathrm{L}^{-1}$. As seen in Fig. 9, the amount of adsorbed BPA on M10 sample increased with an increase of adsorption time and BPA solution concentration. Therefore, the adsorption capacity of BPA can be controlled by changing the adsorption time and BPA solution concentration.

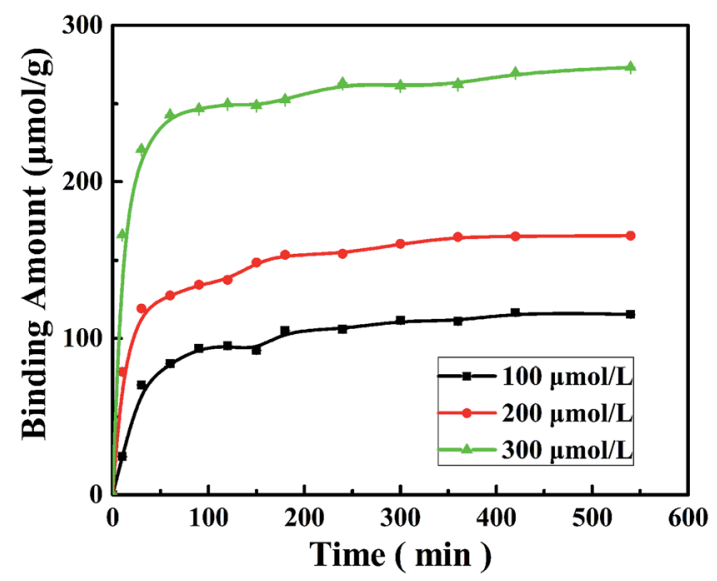

Fig. 9 The binding amounts per unit mass of the M10. 

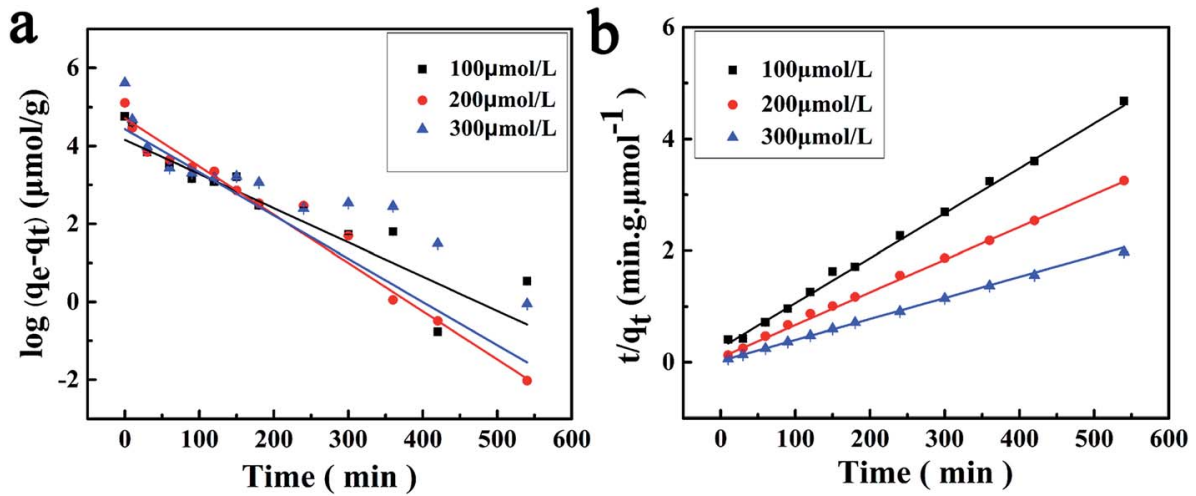

Fig. 10 Applications of the pseudo-first-order adsorption model (a) and pseudo-second-order adsorption model (b) for the adsorption of BPA onto the M10.

In order to investigate adsorption mechanism of M10 microspheres for BPA, the kinetic model equations were employed and the results are shown in Fig. 10 and Table 3. The results showed that the $t / q_{t}$ versus $t$ plots in pseudo-second-order adsorption model for BPA adsorption yielded a better linear relationship. From the slope of the straight line, the theoretical adsorption equilibrium amount with different concentration of BPA can be calculated $\left(123,178\right.$ and $\left.277 \mu \mathrm{mol} \mathrm{g}^{-1}\right)$, and the results were in good accordance with the experimental data as well as the high correlation coefficient $R^{2}(>0.99)$. Therefore, the adsorption of BPA onto PES magnetic microspheres followed to the pseudo-second-order model which considers that the rate of occupation of adsorption sites is proportional to the square of the number of unoccupied sites. Compared with PES electrosprayed microspheres (as shown in Fig. 11), the magnetic microspheres possessed much larger BPA adsorption capacity, and the equilibrium adsorption amounts of M10 had increased significantly to $327.1 \%, 305.4 \%$ and $288.9 \%$, respectively, when the concentration of BPA aqueous solution was 100, 200 and $300 \mu \mathrm{mol} \mathrm{L}{ }^{-1}$. Generally, the affinity to adsorbate molecule could affect the adsorption behavior. Since PES is a kind of hydrophobic polymer, the dispersion of the PES electrosprayed microspheres is limited in water, which limits the adsorption of BPA. While, $\mathrm{Fe}_{3} \mathrm{O}_{4}$ nanoparticles can improve the hydrophilicity of PES microspheres, so the interaction between BPA molecules and microspheres was enhanced. Besides, after the in situ reaction process, the surface of magnetic microspheres became much rougher, which may result in an increased specific surface area. And according to the kinetic model, the adsorption was a kind of physical adsorption process which mainly controlled by the specific

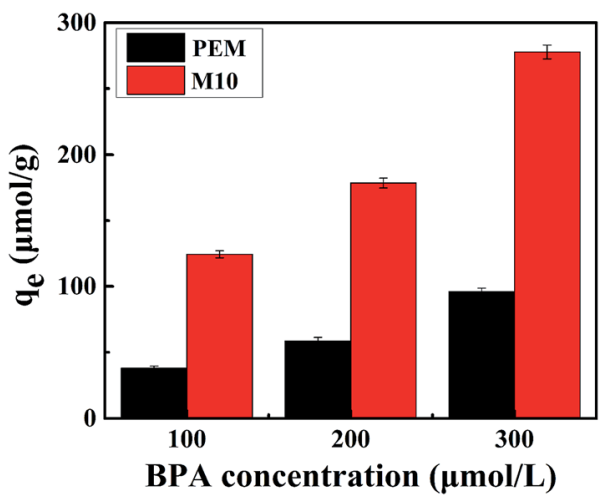

Fig. 11 The adsorption equilibrium amount of BPA onto PEM and the M10.

surface area of the adsorbent. Thereby, adsorption capacity of the microspheres improved. These results demonstrated that both the hydrophilic properties and rough surface of microspheres would affect the adsorption behavior optimistically. Moreover, the microspheres were bathed in boiling water in order to eliminate the residual solvent, and the boiling water would provide anchorage force which enhanced the mechanical force of microspheres to prevent the microspheres from collapse in practical applications. ${ }^{36}$ So the PES in situ magnetic microspheres can be applied to remove endocrine disruptors from their aqueous solutions, and can play an important role in the field of wastewater treatment.

Meanwhile, the reuse performance of the M10 microspheres was also tested as shown in Fig. 12 since the regeneration and

Table 3 The kinetic parameters for the adsorption of BPA onto the M10

\begin{tabular}{|c|c|c|c|c|c|c|c|}
\hline 200 & 165 & 111 & 2.85 & 0.9991 & 178 & 3.75 & 0.9999 \\
\hline 300 & 273 & 84 & 2.55 & 0.7306 & 277 & 5.63 & 0.9995 \\
\hline
\end{tabular}




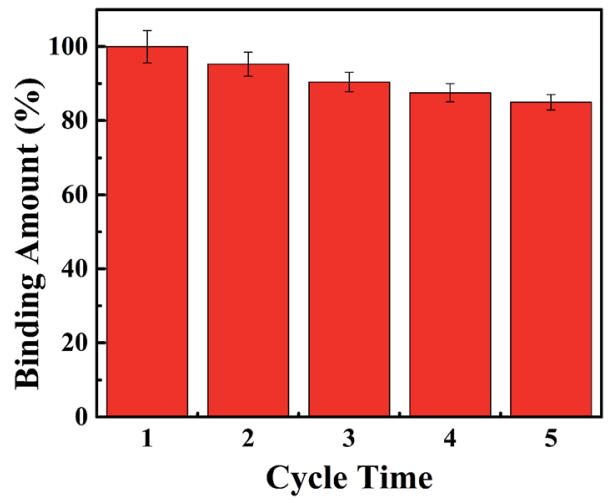

Fig. 12 The reuse of M10 microspheres

recyclability of adsorbent is crucial in improving the processing economy. The results showed that the M10 sample had a good reuse performance. The adsorption capacity of BPA could be more than $80 \%$ of the initial adsorption capacity after five repeated adsorption-desorption cycles. It suggested that the PES in situ magnetic microspheres could be reused for many times without significant loss of adsorption capacity for BPA and had the potential to be applied in industrial activities.

\section{Conclusion}

PES magnetic microspheres were prepared successfully by in situ generation of $\mathrm{Fe}_{2} \mathrm{O}_{3}$ or $\mathrm{Fe}_{3} \mathrm{O}_{4}$ nanoparticles in the pores on the surface of PES electrosprayed microspheres. It is a new and facile method for the preparation of PES magnetic microspheres which have excellent properties. The magnetic microspheres exhibited sensitive magnetic response, superparamagnetic properties and can be rapidly and directional separated from surroundings with applied magnetic field. Moreover, compared with the pure PES electrosprayed microspheres, the prepared PES magnetic microspheres possessed more excellent adsorption capacity for BPA. And the adsorption data fit the pseudo-second-order adsorption model well. Besides, the resultant microspheres also had a good reuse performance. Therefore, the electrosprayed PES in situ magnetic microspheres have significant advantages and a great potential for applications in the field of water treatment and environmental depuration.

\section{Conflicts of interest}

There are no conflicts of interest to declare.

\section{Acknowledgements}

This work was supported by research grants from the Natural Science Foundation of China (51573103, 21274094, 21304060), the National Key Laboratory Project (oic-201701006) and Outstanding Young Scholars Fund of Sichuan University (2015SCU04A25).

\section{References}

$1 \mathrm{~J}$. Xu, L. Wang and Y. Zhu, Decontamination of bisphenol A from aqueous solution by graphene adsorption, Langmuir, 2012, 28, 8418-8425.

2 F. Casado-Carmona, M. Alcudia-León, R. Lucena, S. Cárdenas and M. Valcárcel, Magnetic nanoparticles coated with ionic liquid for the extraction of endocrine disrupting compounds from waters, Microchem. J., 2016, 128, 347-353.

3 C. Li, Z. Wang, A. Sun, R. Liu and C. Diao, Magnetic multiwalled carbon nanotubes matrix solid-phase dispersion with dispersive liquid-liquid microextraction for the determination of ultra trace bisphenol A in water samples, Chromatographia, 2017, 80, 1189-1197.

4 F. vom Saal, S. Nagel, B. Coe, B. Angle and J. Taylor, The estrogenic endocrine disrupting chemical bisphenol A (BPA) and obesity, Mol. Cell. Endocrinol., 2012, 354, 74-84.

5 S. Baharin, N. Muhamad Sarih, S. Mohamad, S. Shahabuddin, K. Sulaiman and A. Ma'amor, Removal of endocrine disruptor di-(2-Ethylhexyl)phthalate by modified polythiophene-coated magnetic nanoparticles: characterization, adsorption isotherm, kinetic study, thermodynamics, RSC Adv., 2016, 6, 44655-44667.

6 R. Wang, D. Huang, Y. Liu, Z. Peng, G. Zeng, C. Lai, P. Xu, C. Huang, C. Zhang and X. Gong, Selective removal of BPA from aqueous solution using molecularly imprinted polymers based on magnetic graphene oxide, RSC Adv., 2016, 6, 106201-106210.

7 L. Zhang, W. Wang, S. Sun, Y. Sun, E. Gao and Z. Zhang, Elimination of BPA endocrine disruptor by magnetic Biobr@SiO $\mathrm{S}_{2} @ \mathrm{Fe}_{3} \mathrm{O}_{4}$ photocatalyst, Appl. Catal., B, 2014, 148, 164-169.

8 I. Bautista-Toledo, M. A. Ferro-Garcia, J. Rivera-Utrilla, C. Moreno-Castilla and F. J. Vegas Fernandez, Bisphenol A removal from water by activated carbon. Effects of carbon characteristics and solution chemistry, Environ. Sci. Technol., 2005, 39, 6246-6250.

9 J. Shen, Z. Li, Y. Wu, B. Zhang and F. Li, Dendrimer-based preparation of mesoporous alumina nanofibers by electrospinning and their application in dye adsorption, Chem. Eng. J., 2015, 264, 48-55.

10 G. Bayramoglu, M. Arica, G. Liman, O. Celikbicak and B. Salih, Removal of bisphenol A from aqueous medium using molecularly surface imprinted microbeads, Chemosphere, 2016, 150, 275-284.

11 K. Zhao, X. Wang, T. Chen, H. Wu, J. Li, B. Yang, D. Li and $\mathrm{J}$. Wei, Bisphenol A adsorption properties of mesoporous $\mathrm{CaSiO}_{3} @ \mathrm{SiO}_{2}$ grafted nonwoven polypropylene fiber, Ind. Eng. Chem. Res., 2017, 56, 2549-2556.

12 F. Imanparast, M. Faramarzi, M. Paknejad, F. Kobarfard, A. Amani and M. Doosti, Preparation, optimization, and characterization of simvastatin nanoparticles by electrospraying: an artificial neural networks study, J. Appl. Polym. Sci., 2016, 133, 43602.

13 W. Mahmood, M. Azarian, W. Wan Fathilah and E. Kwok, Nanoencapsulation of montmorillonite clay within 
poly(ethylene glycol) nanobeads by electrospraying, J. Appl. Polym. Sci., 2017, 134, 45048.

14 F. Qiu, M. Peng, Z. Wei, X. Wang and J. Yang, Preparation of polyethersulfone/sulfonated polyethersulfonephenylethane microspheres and its application for the adsorption of bisphenol A, J. Appl. Polym. Sci., 2015, 133, 43066.

15 P. Li, K. Li, X. Niu and Y. Fan, Electrospraying magneticfluorescent bifunctional Janus PLGA microspheres with dual rare earth ions fluorescent-labeling drugs, RSC Adv., 2016, 6, 99034-99043.

16 M. Peng, L. Wang, Z. Wei, X. Wang, Q. Zhang, S. Long and J. Yang, Structure controlling and adsorption application of polyethersulfone porous microspheres prepared via electrospraying, Chin. J. Polym. Sci., 2014, 32, 1390-1399.

17 Q. Zhang, Y. Zhang, Q. Wei, X. Wang, J. Liu, J. Yang and C. Zhao, Electrosprayed porous microspheres for the removal of endocrine disruptors, J. Appl. Polym. Sci., 2010, 120, 2648-2653.

18 K. Bhattacharya, D. Parasar, B. Mondal and P. Deb, Mesoporous magnetic secondary nanostructures as versatile adsorbent for efficient scavenging of heavy metals, Sci. Rep., 2015, 5, 17072.

19 Z. Jin, X. Wang, Y. Sun, Y. Ai and X. Wang, Adsorption of 4-NNonylphenol and bisphenol-A on magnetic reduced graphene oxides: a combined experimental and theoretical studies, Environ. Sci. Technol., 2015, 49, 9168-9175.

20 H. Zhang, Z. Zhao, X. Xu and L. Li, Study on industrial wastewater treatment using superconducting magnetic separation, Cryogenics, 2011, 51, 225-228.

21 Y. Cao, L. Wen, F. Svec, T. Tan and Y. Lv, Magnetic Au $\mathrm{np} @ \mathrm{Fe}_{3} \mathrm{O}_{4}$ nanoparticles as reusable carriers for reversible enzyme immobilization, Chem. Eng. J., 2016, 286, 272-281.

22 P. Zan, C. Yang, H. Sun, L. Zhao, Z. Lv and Y. He, One-pot fabricating $\mathrm{Fe}_{3} \mathrm{O}_{4}$ /graphene nanocomposite with excellent biocompatibility and non-toxicity as a negative MR contrast agent, Colloids Surf., B, 2016, 145, 208-216.

23 W. Kuan, D. Horák, Z. Plichta and W. Lee, Immunocapture of CD133-positive cells from human cancer cell lines by using monodisperse magnetic poly(glycidyl methacrylate) microspheres containing amino groups, Mater. Sci. Eng., C, 2014, 34, 193-200.

24 Y. Shi, S. Ma, R. Tian, Y. Zhao, Q. Jiao, X. Ma and Q. Shang, Synthesis, characterization and release profiles of nanoparticles self-assembled from poly (PEGMA-co-MMAco-Acryloyl-B-CD) copolymers, Surf. Interface Anal., 2014, 47, 270-277.
25 L. Xie, F. Lan, W. Li, Z. Liu, S. Ma, Q. Yang, Y. Wu and Z. Gu, Polyacrylic acid brushes grafted from $\mathrm{P}(\mathrm{St}-\mathrm{AA}) / \mathrm{Fe}_{3} \mathrm{O}_{4}$ composite microspheres via ARGET-ATRP in aqueous solution for protein immobilization, Colloids Surf., B, 2014, 123, 413-418.

26 J. Zhao, R. Luque, W. Qi, J. Lai, W. Gao, M. Hasan Shah Gilani and $\mathrm{G}$. $\mathrm{Xu}$, Facile surfactant-free synthesis and characterization of $\mathrm{Fe}_{3} \mathrm{O}_{4} @ 3$-aminophenol-formaldehyde core-shell magnetic microspheres, J. Mater. Chem. A, 2015, 3, 519-524.

27 R. Gui, Y. Wang and J. Sun, Encapsulating magnetic and fluorescent mesoporous silica into thermosensitive chitosan microspheres for cell imaging and controlled drug release in vitro, Colloids Surf., B, 2014, 113, 1-9.

28 D. Hritcu, G. Dodi, M. Silion, N. Popa and M. Popa, Composite magnetic chitosan microspheres: in situ preparation and characterization, Polym. Bull., 2011, 67, 177-186.

29 J. Zhi, Y. Wang, Y. Lu, J. Ma and G. Luo, In situ preparation of magnetic chitosan $/ \mathrm{Fe}_{3} \mathrm{O}_{4}$ composite nanoparticles in tiny pools of water-in-oil microemulsion, React. Funct. Polym., 2006, 66, 1552-1558.

30 Y. Wu, Y. Wang, G. Luo and Y. Dai, In situ preparation of magnetic $\mathrm{Fe}_{3} \mathrm{O}_{4}$-chitosan nanoparticles for lipase immobilization by cross-linking and oxidation in aqueous solution, Bioresour. Technol., 2009, 100, 3459-3464.

$31 \mathrm{X}$. Luo, S. Liu, J. Zhou and L. Zhang, In situ synthesis of $\mathrm{Fe}_{3} \mathrm{O}_{4} /$ cellulose microspheres with magnetic-induced protein delivery, J. Mater. Chem., 2009, 19, 3538-3545.

32 Y. Ho and G. Mckay, Kinetic models for the sorption of dye from aqueous solution by wood, Process Saf. Environ. Prot., 1998, 76, 183-191.

33 Y. Ho and G. McKay, Pseudo-second order model for sorption processes, Process Biochem., 1999, 34, 451-465.

34 Q. Zhang, J. Liu, X. Wang, M. Li and J. Yang, Controlling internal nanostructures of porous microspheres prepared via electrospraying, Colloid Polym. Sci., 2010, 288, 13851391.

35 J. Yang, Q. C. Zhang, X. J. Wang, S. R. Long and J. Liu, China Pat., CN101735613 (A), 2010.

36 L. Wang, Q. Zhang, X. Wang, J. Liu and J. Yang, The preparation and forming mechanism of the red blood cellshaped microspheres via electrospraying, J. Appl. Polym. Sci., 2011, 122, 2552-2556. 